\title{
Faculty Development Program on Active Learning for Engineering Faculty in Chile: Sharing Step
}

\author{
Prof. Angeles Dominguez, Tecnologico de Monterrey, Monterrey, Mexico and Universidad Andres Bello, San- \\ tiago, Chile
}

Angeles Dominguez is a Professor of the Department of Mathematics within the School of Engineering, a researcher at the School of Education, and Associate Dean of Faculty Development at the School of Medicine and Health Sciences at the Tecnologico de Monterrey, Mexico. Also, she is currently collaborating with the School of Engineering at the University Andres Bello at Santiago, Chile. Angeles holds a bachelor degree in Physics Engineering from Tecnologico de Monterrey and a doctoral degree in Mathematics Education from Syracuse University, NY. Dr. Dominguez is a member of the Researchers' National System in Mexico (SNI-1) and has been a visiting researcher at Syracuse University, at UT-Austin and at Universidad Andres Bello. She teaches undergraduate courses in Mathematics, graduate courses in Education, and is a thesis advisor on the master and doctoral programs on education at the Tecnologico de Monterrey. Her main research areas are: models and modeling, use of technology to improve teaching and learning, gender issues in STEM education.

\section{Prof. Maria Elena Truyol, Universidad Andres Bello, Santiago, Chile}

María Elena Truyol, Ph.D., is full professor and researcher of the Universidad Andrés Bello (UNAB). She graduated as physics teacher (for middle and high school), physics (M.Sc.) and Ph.D. in Physics at Universidad Nacional de Córdoba, Argentina. In 2013 she obtained a three-year postdoctoral position at the Universidade de Sao Paulo, Brazil. Her focus is set on educational research, physics education, problem-solving, design of instructional material and teacher training. She teaches undergraduate courses related to environmental management, energy and fundamentals of industrial processes at the School of Engineering, UNAB. She currently is coordinating the Educational and Academic Innovation Unit at the School of Engineering (UNAB) that is engaged with the continuing teacher training in active learning methodologies at the three campuses of the School of Engineering (Santiago, Viña del Mar and Concepción, Chile). She authored several manuscripts in the science education area, joined several research projects, participated in international conferences with oral presentations and key note lectures and serves as referee for journals, funding institutions and associations.

Prof. Genaro Zavala, Tecnologico de Monterrey, Monterrey, Mexico and Universidad Andres Bello, Santiago, Chile

Genaro Zavala is a Full Professor and Director of Undergraduate Studies in the School of Engineering and Sciences at Tecnologico de Monterrey. Professor Zavala is National Researcher Level 1 of the National System of Researchers of Mexico and leads the Physics Education Research and Innovation Group. He works with the following research lines: conceptual understanding of students on subjects of physics, transfer of understanding between the different areas of knowledge, use of technology in learning, impact of using innovative learning environments and development of assessment tools. He has 91 articles in refereed journals and conferences, over 610 citations according to Scopus, 6 books, 14 book chapters, 142 national and international presentations in countries like Korea, Denmark, Hungary, Cuba, United States, Chile, Ecuador and Argentina and 29 international workshops in Mexico, Chile, Argentina and Italy. Genaro Zavala was appointed to the editorial board of the Physical Review Special Topics-Physics Education Research journal of the American Physical Society for the period 2015 to 2018, vice president of the Latin American Physics Education Network (LAPEN) for the period 2013-2015 and is currently the coordinator of the Topical Group: Evaluation of Learning and Instruction of the International Group for Research and Teaching of Physics (GIREP by its French acronym). Dr. Zavala is a member of the American Association of Physics Teachers (AAPT) where he was vice president candidate, a member of the Committee on Research in Physics Education (RIPE) a member and chair of the International Education Committee and elected member of Leadership Organizing Physics Education Research Council (PERLOC) in the period 2015-2018. 


\title{
Faculty development program on active learning for engineering faculty in Chile: Sharing step
}

\begin{abstract}
This work in progress presents the structure and results of one part of an ongoing faculty development program in a large private university in Chile. The entire development program consists of six steps; in this paper, we focus on the fifth step, sharing, for two reasons: 1) some of the previous steps have been already presented and 2) the authors are interested in receiving feedback on the step in which sharing and spreading experiences on active learning implementations occur.

For this presentation, we focus on the structure, materials shared and products that resulted from the 2-day workshop, the fifth step of the program. All participants work collaboratively in small groups, by the engineering subject, to design an active learning activity that will challenge students and convey the learning objectives of the course/unit selected. In this workshop, there were about 80 participants, 20 of those had continually participated in the previous steps. The authors are interested in receiving feedback on the program, particularly of the step in which sharing and spreading experiences on active learning implementations occur.
\end{abstract}

\section{Introduction}

Many countries are carrying out actions with the aim of increasing the number of professionals in the STEM areas. To this end, they are making recommendations aimed at favoring the adoption of empirically validated teaching practices that help achieve that objective by increasing retention, encouraging inclusion, favoring timely titling, etc. [1].

Particularly in the case of engineering, since a couple of decades ago there is the consensus with regards to producing changes in the way professional training is conceived. That is, teachers need to abandon the role of information providers, while students must leave the passive role of recipients of that information. It is necessary to transform it into a model with a focus on the student and on their learning [2], [3], [4].

We need to motivate teachers to change their teaching and learning paradigm by creating opportunities that allow them to reflect and rethink their practices. They will be willing to change when they entertain the possibility of increasing classroom interactions and decrease teacher control while achieving the course objectives and improving learning outcomes. In this scenario, the Continuous Faculty Development Program and the Workshop on Active Learning in Engineering at the School of Engineering are designed to provide tools that allow the teacher to incorporate active learning methodologies in their teaching under the following assumptions:

i. Active learning strategies are central to professional development in engineering [1], [5].

ii. Methodological innovations are difficult to adopt by a large percentage of teachers [2], [6].

iii. An institutional training program needs a convergence of conditions to sustain effectiveness: institutional support, economic and human resources, collaborative culture, and basic agreements and decisions on the characteristics of the educational system to be achieved [7].

iv. Knowledge is situated in the day-to-day lived experiences of teachers and best understood through critical reflection with others who share the same experience [8].

v. Learning communities actively engage teachers in professional learning courses, increase their professional knowledge and enhance student learning [8], [9]. 
vi. Mastering teachers with generic teaching skills is not that effective. We need to go to the core of teachers' conceptions about teaching and learning to generate fundamental changes in their practice to improve their students' learning outcomes [10].

vii. It is possible to assess the effect of a professional development program by identifying and comparing the conceptions of teaching before and after the program [10], [11].

The proposed workshops and activities allow the participants to understand the need of a paradigm shift in teaching, design and implement educational innovation projects aimed at solving current problems related to quality in higher education, and evaluate the intervention as well as the design. A particular emphasis of this faculty development program is on promoting an exchange of experiences among participants, with the aim of building a learning community that lasts over time. This exchange of experiences is the focus of this work: the sharing step. First, we briefly describe the whole program structure to set a base on the sharing step.

\section{Structure of the proposal}

As we presented at ASEE 2017, [2], we designed a program for in-service teacher preparation of the engineering faculty in a large private university. This program is specially designed to promote and ensure the use of Active and Innovative Methodologies and to strengthen a learning community that can sustain over time the usage of these methodologies.

The three-semester faculty development program consists of six sequential steps (Fig. 1). We alternate from all full-time faculty (around 80) to a selected subgroup (about 20 participants); that is, in steps 1, 3 and 5 all professors are invited, while in steps 2,4 and 6 we work very closely with the selected group. The activities for all faculty are short: 1) the Workshop on Active Learning in Engineering lasts two days and faculty moves to the Main Campus, and 2) the seminar is two hours long, and the invited guest delivers a talk at each of the three sites (three different cities). The activities for the selected group, Continuous Faculty Development Program, last one academic semester each and take place at each of the three campuses in different cities.

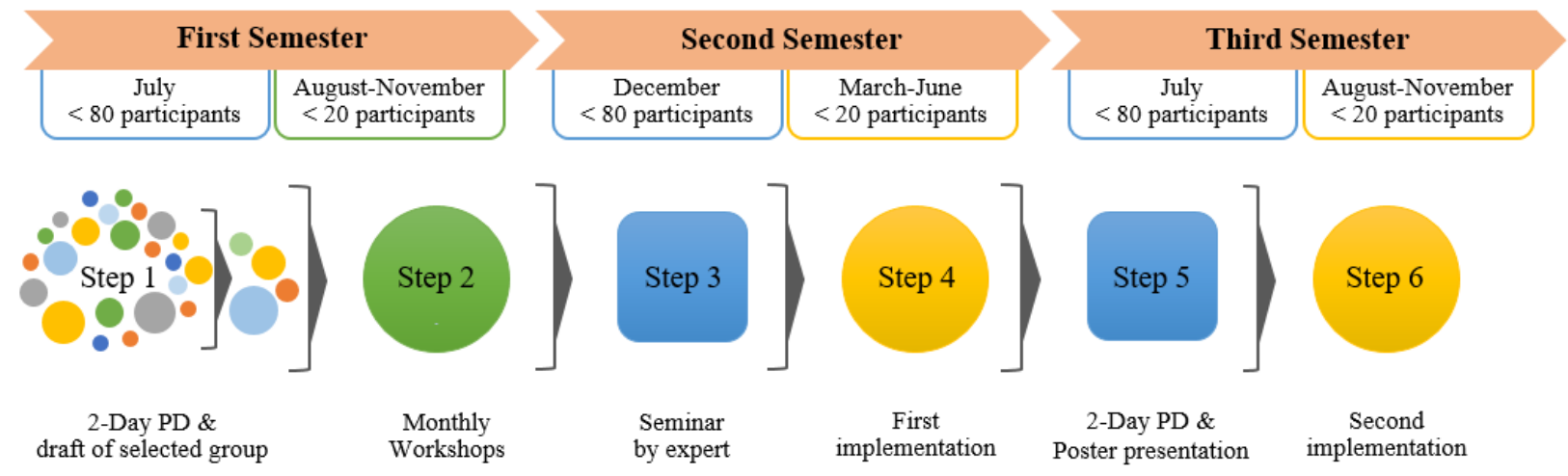

Fig. 1. Six sequential steps program. Steps 1, 3 and 5 are open for the entire full-time faculty and are short (one or two days). Steps 2, 4 and 6 are closed activities for the selected group of participants and last one academic semester each.

Previous works [2], [11], suggest an approach to professional development that is based on the conceptual change theory [12] and pays attention to four separate elements: 
1) Self-reflection, participants undergo self-reflection and clarify personal conceptions;

2) Confrontation, participants are brought to realize possible inadequacies in their existing conceptions and teaching practices and thus create awareness for the need to change;

3) Exposure, workshop facilitator provides a direction and a model for improvement;

4) Commitment building, workshop facilitator encourages teachers to engage in changes and development.

The entire program uses conceptual change approach as a framework in a recursive way [11], [12]. That is, the conceptual change approach is used to structure the entire program, as well as three of the steps within the program (Step 1, 2 and 5). For further description of the six sequential steps and a study of the assessment and effect of the program, see [2].

\section{Workshop on Active Learning in Engineering: focus on collaborating and sharing experiences - Step 5}

The fifth step, Workshop on Active Learning in Engineering (WALE), is a two-day workshop for all full-time engineering faculty in which the participants of the steps 2 and 4 share their experiences. Also, there is a panel discussion and plenary conferences by experts on implementing a new educational model. Two issues are central to the design of the activities to be carried out during the two-day training for all faculty. First, the relevance of a faculty development program that focuses on strategies that report having worked in the discipline at the university level rather than teaching strategies for general education [2]. Second, the need to socialize teaching innovation experiences to motivate more participants in the task, making them realize that it is possible to design and implement active learning activities that capture students' attention and empower them about their own learning.

In addition to the discussion panel and the plenary sessions, two activities were designed in which the participants were the center of their learning process regarding the introduction of active-learning methodologies in the classroom. One of the activities consists of two sessions of four hours each in which the teachers, working in groups, face the challenge of learning relevant aspects of the Problem-Based Learning (PBL) methodology, through an activity designed with the PBL methodology itself. The second activity, a poster session where the participants of Step 2 share their teaching innovation experience implemented during the previous semester (Step 4). Below we present a brief description of these experiences.

\section{Poster session}

Sixteen innovations were presented, corresponding to the works developed by the participants of the Continuous Faculty Development Program (Steps 2 to 4). This group of professors was selected in August 2016 due to institutional recommendations, based on previous experience in general education strategies. They participated in steps 1,2,3 and 4 of the program. There were three hours for the presentations in a way that all the participants of the workshop could see all the posters. This activity generated a very favorable moment to exchange experiences; participants highly valued this activity according to a satisfaction survey conducted after the workshop. The development of new ideas for innovations, the generation of contacts between 
teachers who saw the possibility of working together and the motivation of many other teachers to generate innovations in their classrooms were the most important results of this activity.

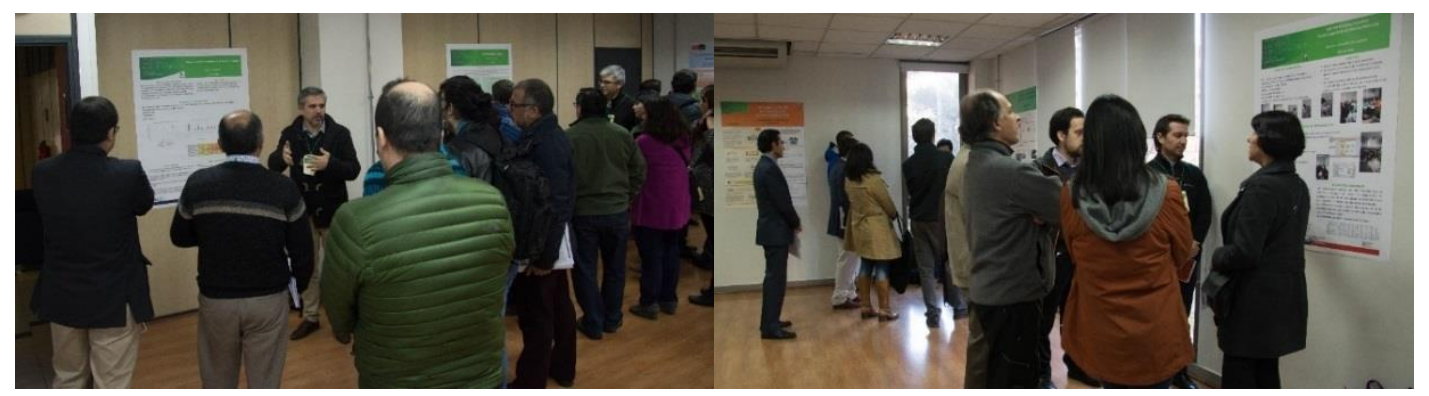

Fig. 2: Poster Session during the 2-day workshop

Photographs of Fig. 2 show participants of the Continuous Faculty Development Program presenting and other participants listening to the experience. Different personalities such as the Dean and Associate Dean of the School of Engineering, Academic Vice President and the General Director of Teaching of the university also attended to the poster presentation. Having the full support of the School has been fundamental in sending a clear message of the importance of the change from a traditional teaching paradigm to one based on active learning.

\section{Collaborative work on PBL}

The Workshop on Active Learning in Engineering of Step 5 included a 2-days workshop, 4 hours each, with 18 groups of 4 or 5 participants of the same or similar engineering subject. They faced the activity in a way that emulates a PBL activity. In this case, the objective was to design a PBL activity for their courses.

The 18 innovations proposed at the end of the sessions varied significantly regarding the topics they involve, the area of contextualization of the problem, the difficulty that the solution process presents, etc. It exceeds the interest of this work to make some judgment on the quality of them. However, in the context of the workshop, six of the designs developed by the groups were presented. A moment for the exchange of ideas and feedback from peers was created to continue emulating the role we want teachers to have with their students: the trainers acted as a guide on the activities, without interfering in the processes of creation and learning of the different groups.

We can infer the impact of this activity from the analysis of the written reflections requested from the groups. These reflections mark the points that, for the teachers are central in the application of this methodology.

During the processes of this activity, the groups reflected on:

- type of knowledge developed with the activity,

- questions arising in the development of the activity,

- aspects to consider in the implementation of the designed activity.

In the case of the "type of knowledge developed with the activity" and besides of how to design a PBL activity, participants mentioned some more frequently. Those were: a) the importance of 
the active learning and the collaborative learning in PBL, b) the importance of the autonomous work of students and c) the importance of working on problems with real contexts. They also mentioned: d) the importance of selecting the activity regarding the learning objectives and e) the recognition of the possibilities of working with active learning.

Secondly, in the case of the "questions arising in the development of the activity" participants reflected mostly on procedural questions. The most frequent were: a) the estimation of the time needed for the activity, b) determination of proper resources, c) how to create an interactive and adequate collaborative work, d) how to correctly formulate the problem both for its clear understanding and for the achievement of the learning objectives, and, e) how to develop the teacher's role as a guide and the generation of evaluation criteria.

Finally, regarding the "aspects to consider in the implementation of the designed activity," they highlighted a) the time required for this type of work, b) the number of students in the course, c) the motivation and involvement generated by the proposed activity, and d) the connection with real problems and everyday situations for students.

TABLE I

RELATIONSHIP OF TOPICS OF THE PBL ACTIVITIES PROPOSED BY EACH OF THE 18 TEAMS DURING THE SECOND DAY OF THE WORKSHOP (CLOSING ACTIVITY)

\begin{tabular}{lll}
\hline Team & \multicolumn{1}{c}{ Career } & \multicolumn{1}{c}{ Title/theme of the problem proposed } \\
\hline 1 & Industrial engineering & Determination of optimal routes for dispatches \\
2 & Industrial engineering & Improvement of waiting time in pediatric emergency rooms \\
3 & Industrial engineering & Characterization of the public transport system of Santiago \\
4 & Geo. / Mining / Metallurgical Eng. & $\begin{array}{l}\text { Pre-feasibility evaluation of gold deposit } \\
\text { Challenge of the } 500 \text { pesos }\end{array}$ \\
5 & Industrial Engineering & $\begin{array}{l}\text { Temperature monitoring in vineyards and early warning system } \\
\text { Determination of tectonic plate velocity and underwater }\end{array}$ \\
6 & Automation and robotics Eng. & morphology \\
7 & Geology & Classification, protocols, and responsibilities in construction \\
8 & Construction engineering & accidents \\
& Connectivity between two populations \\
9 & Civil engineering & Small business strategic plan design \\
10 & Informatics engineering & Support of underground excavations at great depth \\
11 & Mining engineering & $\begin{array}{l}\text { Gasoline sensor by flotation } \\
\text { Watershed morphology and reservoir of hydrocarbon }\end{array}$ \\
12 & Engineering School, Physics & Determination of the optimal location of the photovoltaic solar \\
14 & Industrial engineering & plant \\
& & Algorithm design for calculation of ingredients \\
15 & Computer and Informatics Eng. & Procedures to follow with missing documentation of ships \\
16 & Engineering in maritime transport & $\begin{array}{l}\text { Elimination of impurities and obtainment of pure copper sulfate } \\
\text { concentrate }\end{array}$ \\
17 & Metallurgical engineering & Generation of the automatized solution to reduce document \\
& & processing times in large repositories of work contracts \\
\hline
\end{tabular}




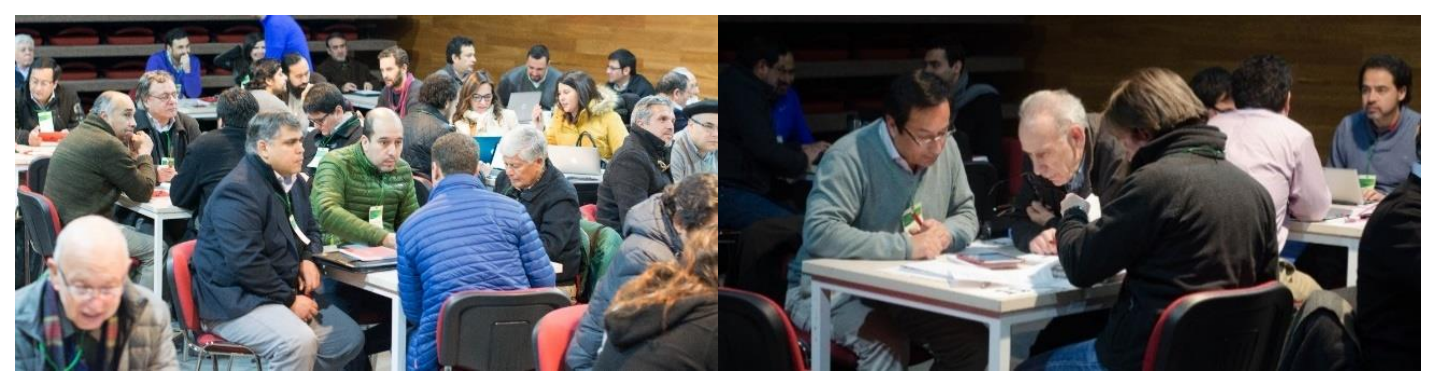

Fig. 3: Collaborative work to design activity in PBL

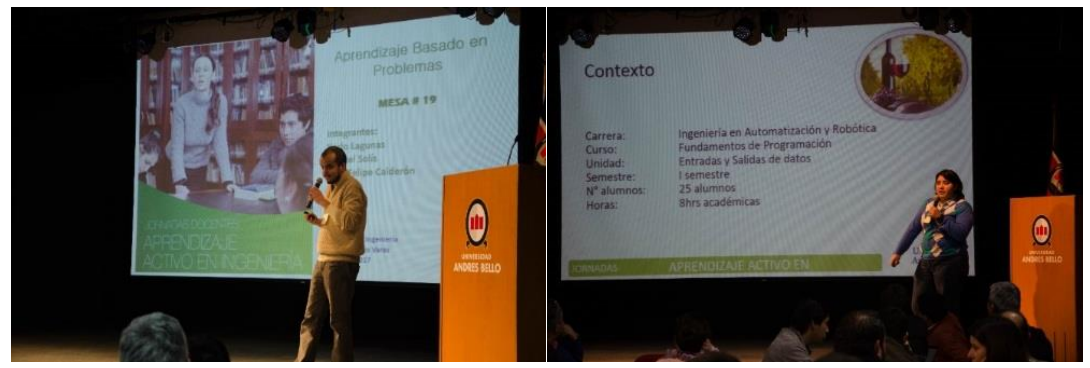

Fig. 4: Sharing the PBL activity designed

The above pictures show two moments of the collaborative work: designing (Fig. 3) and sharing (Fig.4). For the designing of a PBL activity, participants were seated according to their engineering subject in groups of 3 to 5 members. The university has campuses in other cities, but the programs are the same for all. Therefore, participants were assigned to their groups based on their area of expertise favoring collaboration among faculty members from all campuses. For the sharing of the PBL activity, all teams uploaded their activity to a shared folder (Google Drive). Participants were asked to present their design and audience was encourage to ask questions (Fig. 4). About one-third of the groups showed their work.

\section{Impact of the Workshop on Active Learning in Engineering}

Without any doubt, the activities carried out in the workshop of 2017 generated a lot of interest for teachers to introduce active learning in their classrooms. Therefore, the second call for the Continuous Faculty Development Program was made through personal submission. Given the high response, it was necessary to carry out a selection process; the applications were more than the open quota. Out of 32 applications received, 25 participants were selected. In this way, three working groups were created (one in each campus) that are highly motivated and committed to the task. There has been an improvement in the rate of attendance at the workshops and the design of proposal compared with the first year of the program. So far, there have been only three dropouts due to the addional administrative work participants have since, some of them have an accreditation process at the university. This new group of 22 professors is going to be implementing their first innovations (Step 4 of Fig. 1) between March and June in 2018 and will present their experience in July 2018 (Step 5).

Institutional support and recognition are required to generate a learning community in the introduction of active learning methodologies in the classroom, which sustains itself over time. 
This is another part of the objective pursued with the "sharing step" of our work. Four participants of the first generation of the Continuous Faculty Development Program presented their innovations at an international conference in Mexico in 2017. They were recognized by the Engineering School with a grant to afford the attendance. Two of them were given the "Innovation in Teaching Award" from the Faculty of Education of the institution where this program is implemented. This acknowledgment is significant because only three professors were recognized of the whole university, and two of them were participants of our program [13]. The last impact of this work was the attainment of the "Recognition of Outstanding Academic Management" for the work project presented in this paper at the UNAB Academic Council 2018 held in January. This recognition was granted to the authors of this paper. At the same Council, another faculty member of the first generation of participants to the program was recognized as an "Outstanding Faculty" for his innovation in class.

\section{Conclusions, further directions and learnings}

This work presents one step (Step 5) out of six that constitute a three-semester faculty development program. This step is relevant since focuses on sharing: a) all full-time faculty participating during the two-day program and 2) poster session of instructors' implementation of active learning during the academic semester (implementation occurred in Step 4).

The entire faculty was able to design PBL activities for different topics by working in groups organized by discipline and sharing their design with everyone. All documents were sent to all faculty members to open up the discussion and share their activity. Six teams presented their design and received feedback from the audience.

The poster session was compelling. It showed that it is possible to incorporate active learning activities in an Engineering course with only one year of training. By sharing their experience, other professors may realize that we are not looking for perfection, but rather flexibility to lose control of time, and knowledge to empower students in their learning.

One of the main lessons learned in this process has to do with something that as trainers we commit, that is, the improvement in the quality of learning from group activities and the importance of peer-to-peer discussions. In this opportunity, all the training sessions focused on teachers' needs, in fostering environments of dialogue and debate. Activities were generated where they could take advantage of all their potentials, their years of experience in the classrooms, their professional experience in each of their areas, but in a creative way, which invited them to rethink their actions. The team of trainers maximized with them the same type of processes that are requested for the students. And, like what happens with the students, the productions and the learning were more powerful, flexible and, hopefully, long-lasting.

\section{Acknowledgments}

We would like to thank the Engineering School of Universidad Andres Bello for all the support received throughout this project and the participating faculty for all the enthusiasm and patience in the development of the workshops and activities. 


\section{References}

[1] S. Freeman, S. Eddy, M. McDonough, M. Smith, N. Okoroafor, H. Jordt and M. Wenderoth, "Active learning increases student performance in science, engineering, and mathematics" in Proc. of the National Academy of Sciences of the United States of America, 111(23), 8410-8415, 2014, DOI: 10.1073/pnas.1319030111, 2014

[2] G. Zavala, M. E. Truyol, and A. Dominguez, "Professional development program in active learning for Engineering Faculty in Chile: First stage", in Proc. of the 2017 ASEE Annu. Conf. and Expo., Columbus, OH June 25-28, 2017, https://peer.asee.org/28761

[3] M. Christie and E. de Graaff, "The philosophical and pedagogical underpinnings of Active Learning in Engineering Education," European Journal of Engineering Education, 42(1), 5-16, 2016, DOI: 10.1080/03043797.2016.1254160

[4] N. L. Fortenberry, "An Extensive Agenda for Engineering Education Research" Journal of Engineering Education, 95(1), 3-5, 2006, doi:10.1002/j.2168-9830.2006.tb00872.x

[5] M. Prince, "Does Active Learning Work? A Review of the Research" Journal of Engineering Education, 93(3), 223-231, 2004.

[6] C. Finelli, D. Shanna, and K. M. Richardson, "Bridging the research-to-practice gap: Designing an institutional change plan using local evidence" Journal of Engineering Education, 103(2), 331-361, 2014.

[7] G. Zavala, H. Alarcón, and J. Benegas, "Innovative training of in-service teachers for active learning: A short teacher development course based on Physics Education Research", Journal of Science Teacher Education, 18(4), 559-572, 2007

[8] V. Vescio, D. Ross, and A. Adams, "A review of research on the impact of professional learning communities on teaching practice and student learning" Teaching and Teacher Education, 24(1), 80-91, 2008.

[9] K. Vangrieken, C. Meredith, T. Packer, and E. Kyndt, "Teacher communities as a context for professional development: A systematic review" Teaching and Teacher Education, 61 (1), 47-59, 2017.

[10] A. Ho, D. Watkins, and M. Kelly, "The conceptual change approach to improving teaching and learning: An evaluation of a Hong Kong staff development program" Higher Education, 42, 143-169, 2001.

[11] C. M. Walter, and C. H. Kautz, "Conceptual change" as a guiding principle for the professional development of teaching staff", in Proc. of the 122 ASEE Ann. Conf. \& Expo., Seattle, WA., 2015.

[12] G. J. Posner, K. A. Strike, P. W. Hewson, and W. A. Gertzog, "Accommodation of Scientific Conception: Toward a Theory of Conceptual Change," Science Education, 86, 211-227, 1982.

[13] Universidad Andres Bello, Dirección de Comunicación Estratégica y Prensa, Destacado Portada section, Nobember 6, 2017, http://noticias.unab.cl/destacado-portada/grupo-altorendimiento-ingenieria-comercial-obtuvo-1o-lugar-iv-concurso-innovacion-pedagogicaunab/ 